\title{
The Present Situation and Development Trend of 10G PON Technology
}

\author{
Ling Leng ${ }^{1, \mathrm{a}}$ Lin Wang $^{2, \mathrm{~b}}$ BenLai Liang ${ }^{1, \mathrm{c}}$ JiangDe $\mathrm{Yu}^{1, \mathrm{~d}}$ \\ ${ }^{1}$ Computer Engineering,ZhongShan PolyTechnic Institute GuangDong ZhongShan,China \\ ${ }^{2}$ ZhongShan Technical Secondary School GuangDong ZhongShan,China

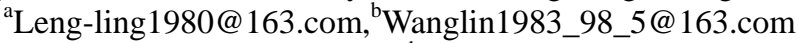 \\ c187198468@qq.com, ${ }^{\mathrm{d}} 412956565 @ q q . c o m$
}

\begin{abstract}
With the development of the mobile Internet, cloud computing, physical networking and triple play, data flow grows rapidly. It brings huge test to operators' network. 1G PON will soon face to the problem of bandwidth bottlenecks, so the demand for 10G PON scale commercial deployment is standing out.10G PON technology is the necessary choice for the development and evolution of the next generation of PON. Although there are the frontier techniques of WDM-POM、 40G PON, however, they are being researched now. It needs a long time for application. For the PON technology, EPON and GPON are the current main technical standards.
\end{abstract}

\section{Keywords-EPON;GPON;10G PON; cloud computing}

\section{THE DEVELOPMENT BACKGROUND OF 10G PON TECHNOLOGY}

The network structure and characteristic of EPON/GPON are inherited by 10G PON technology, which is the access technology of Point-to-Multipoint, made of the bureau side optical line terminal (OLT), the user side Optical Network Unit (ONU) and Optical Distribution Network (ODN). Active equipment is set in the local side and the user side, while fiber and passive components are used in the middle. With similar to the original PON, 10G PON is classified into $10 \mathrm{G} \mathrm{EPON}$ and $10 \mathrm{G}$ GPON. At the foundation of IEEE 802.3av standard, 10G EPON uses the contents of the IEEE 802.3 ah as many as possible. Its upward compatibility is very good. While the upload bandwidth and download bandwidth of 802.3ah standard is expanded to10G bit/s rate. The problem of compatibility with $1 G$ EPON is considered. So relevant physical parameters are set to make the Optical Network Unit for 10G EPON and 1G EPON coexist in the same Optical Distribution Network. At the same time, there isn't any change for configuration of the Optical Distribution Network. It saves the early investment for operators.

While for 10G GPON, with the foundation of ITU - T G..987 protocol group, a series of standards are defined including general characteristics, physical media related layer, TC layer and management control interface. There are two main structures of $10 \mathrm{G}$ GPON put forward. They are XG PON1 (upstream and downstream asymmetrical) and XG PON2(upstream first symmetrical).The standards of related asymmetrical parameters are started to formulate.

\section{ANALYSIS OF 10G PON TECHNOLOGY}

As shown in figure 1, through development history of PON technology, it can be found that every kind of PON technology needs four stages from birth to large-scale commercial applications.They are formulating technical standards, developing relevant chips and optical modules, establishing Experiment Bureau and deploying commercial production。It lasts about five years, while the development of every stage experiences many times of demonstrated and repeated.

A. 10G PON basic form----Stack with 1G PON through the stacking of WDM

Considered the protection for fiber system operators have established, the ODN of 10G PON must make use of network topology of $1 \mathrm{G}$ PON, optical fiber and splitter in existed $1 \mathrm{G}$ PON network. Firstly, stack with $1 \mathrm{G}$ PON is realized. Then, evolution from $1 \mathrm{G}$ PON to $10 \mathrm{G}$ PON is completed by interface boards of supporting $10 \mathrm{G}$ added in OLT side to replace ONT/ONU.

To realize stack with $1 \mathrm{G}$ PON in the same ODN, 10G PON adopts the upload and download wavelength planning, which is different from $1 \mathrm{G}$ PON. The compatibility between $10 \mathrm{G}$ PON and $1 \mathrm{G}$ PON is achieved by the stacking of waveform division. It works that by WDM1r devices placed in the Central Office, waves are composited or decomposited for multiple work signals in upstream and downstream, combined with previa or embedded WBF devices in terminal. As shown in figure 2

Based on the stack, the evolution of $10 \mathrm{G}$ PON is provided to realize. When upgrading, operators can choose to upgrade part of the user equipments on the ODN or change for the next generation of equipments. The difference of upgrading between $1 \mathrm{G}$ PON and 10G PON system is the length of time. To upgrade from $1 G$ PON to 10G PON, wavelength plan must be followed with the ITU - T G 984.5 amd1 (extended band) standard by all ONU and OLT.

B. 10G PON physical layer----whole dilation

The most basic demand for the "beyond 1G PON age" system is to provide more than $1 \mathrm{G}$ PON higher data transmission rate. Therefore, the standard of $10 \mathrm{G}$ PON is that download is $10 \mathrm{G}$, upload is $2.5 \mathrm{G}$, average bandwidth of download and upload promotes respectively 4 times and 2 times than $1 \mathrm{G}$ PON. In addition, compared to $1 \mathrm{G}$ PON, there are obvious changing in branch ratio, optical power budget, transmission distance and other physical specifications for 10G PON. As shown in figure 3.

C. 10G-PON transmission convergence layer - still using basic mechanism, strengthening function, improving efficiency 
The core elements of TDM PON system is TC layer. By three key technologies (framing, dynamic bandwidth allocation and activation), it guarantees to realize multi-points access. The TC layer of 10G-PON still uses basic mechanism of 1G-PON TC layer, on this basis, the necessary improvement has got.

To adapt 10G rate, use chip and improve processing efficiency, framing structure for 10G- PON is improved in details. It makes data fragmentation less splicing, easier to align. The basic mechanism of DBA remains unchanged. The distributing flexibility is further enhanced. The activation process of $10 \mathrm{G}$ PON is according to $1 \mathrm{G}$ PON. The management information system of physical layer is further simplified. Robustness is improved. As the demand of operators gradually clear up, compared to $1 \mathrm{G}$ PON, 10G PON has obvious expansion in secure and energy saving. In secure, 10G PON not only has implemented verification of terminal equipment in the activation process of TC layer, but also has improved he key switch process in the normal working state and its robustness. Besides, 10G PON provides new extra security guarantee mechanism, for example, upstream encryption and downstream multicast encryption.

Energy saving has always been a disputable topic. In $1 \mathrm{G}$ PON period, ITU - T developed G.sup45 (namely G-PON energy saving white paper) as PON energy saving guide material. The chip level energy saving technology is described as the core of the ONU energy saving state machine consisted of the different degree of energy-saving model in this white paper. With the energy saving appeal gradually rising in the world, at the basis of $1 \mathrm{G}$ PON energy saving white paper, doze mode and cyclic sleep are chose as standard energy saving modes for 10G PON. Among them, doze mode has to be chose to realize, cyclic sleep is chosen to realize. The difference between them is that the former only closes the ONU transmitter, while the latter closes transmitter and receiver at the same time, which is deeper sleep technology.

\section{THE DEPLOYMENT WAY OF 10G PON TECHNOLOGY}

According to technical characteristics of 10G PON network, independent deployment way and mixed deployment way have different features.

A. Independent deployment way

This way calls for the interface of OLT to access only the ONU of 10G PON, not PON (GPON or EPON), to keep the independence of 10G PON, its features are as below:

(1) Due to strictly distinguish of the system and technology, it is beneficial to service fulfillment and network maintenance;

(2) Independent deployment can play the biggest access ability of $10 \mathrm{G}$ PON, guarantee $10 \mathrm{G}$ PON to operate with the greatest access bandwidth and the biggest customer access amount. It avoids optical power waste in mixed mode.

(3) With 10G PON system only is opened, the cost of OLT equipment can be reduced.

(4) When the number of customers is not big in EPON and GPON system, independent deployment way will increase the number of interface-board for 10G PON, it results that construction cost is higher.

In practical projects, if independent deployment way is chosen, 10G PON and PON (GPON or EPON) would not share sub-frame, be distinguished with sub-frame to maintain system clarity for OLT equipment.

B. Mixed deployment way

In this way, 10G PON ONU and PON (GPON or EPON) ONU are accessed in the same 10G PON interface according to the business needs at the same time. While its features are as below:

(1) Because there is no accurate distinguish of the system and technology, it is not beneficial to service fulfillment and network maintenance;

(2) Mixed deployment will affect access ability of 10G PON, it cannot make system reach upstream rate of 10Gbit/s for 10G EPON.

In network deployment, 10G PON and PON (GPON or EPON) are transmitted in a fiber, accessed to two different ONU by one optical splitter, which makes that it is impossible to work as the state of maximum amount of customer access for system, causes waste of optical power.

Usually, the size of the access network is very large, especially PON network, because it needs to face directly the ultimate customers, so the number of ONU equipments on customer side and PON systems are very big. The slight differences of individual maintenance can bring enormous pressure to maintain by amplification of network scale. From this perspective, independent deployment way has obvious advantages. In addition, at the foundation of analysis of system bandwidth, mixed way can't play the best access ability of 10G PON. But the business development trend is broadband and flexible. It is not absolutely available to reduce cost at the price of the network access ability. It seemed that independent deployment way is useful in the network scale deployment.

\section{CONCLUSION}

The technology of 10G PON accords with "big capacity, less Central Office " the developing direction of for future access network. It can improve access rate, support bigger assigning ratio, as well as cover more users. Therefore, 10G PON technology will become the popular technology for the sustainable development of broadband network construction, which can help the operators realize "raising speed by broadband ", "the light for copper " in future.

\section{REFERENCE}

[1] IEEE 802.3. IEEE standard for information technology Telecommunications and Information Exchange Between Systems - Local and Metropolitan Area Networks - Specific Requirements - Part 3: Carrier Sense Multiple Access with Collision Detection (CSMA/CD) Access Method and Physical Layer Specifications[S].2008.

[2] ITU-T G.987.1. 10 Gigabit-Capable Passive Optical Network (XG-PON) General Requirements [S]. 2009.

[3] ITU-T G.987.2. 10-Gigabit-Capable Passive Optical Networks (XG-PON): Physical Media Dependent (PMD) Layer Specification (for consent) [S].2009.

[4] ITU-T G.987.3. XG-PON Transmission Convergence Layer Specification [S]. 2009. 
[5] ITU-T G.988. ONU Management and Control Interface Specification

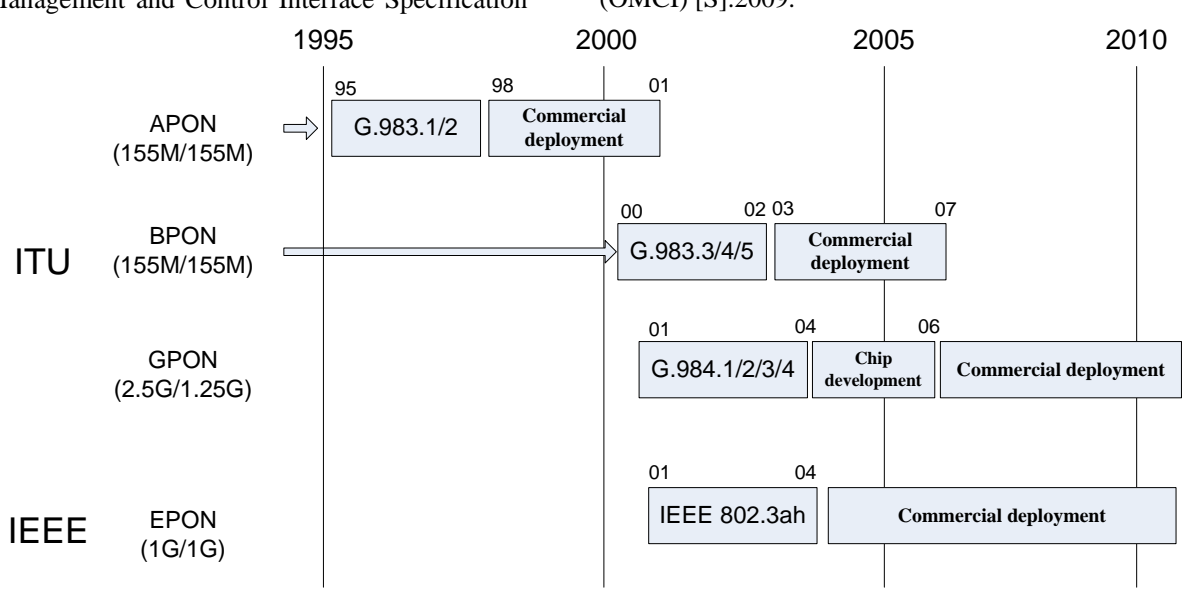

Figure 1 Summary of PON Technology Development Experience

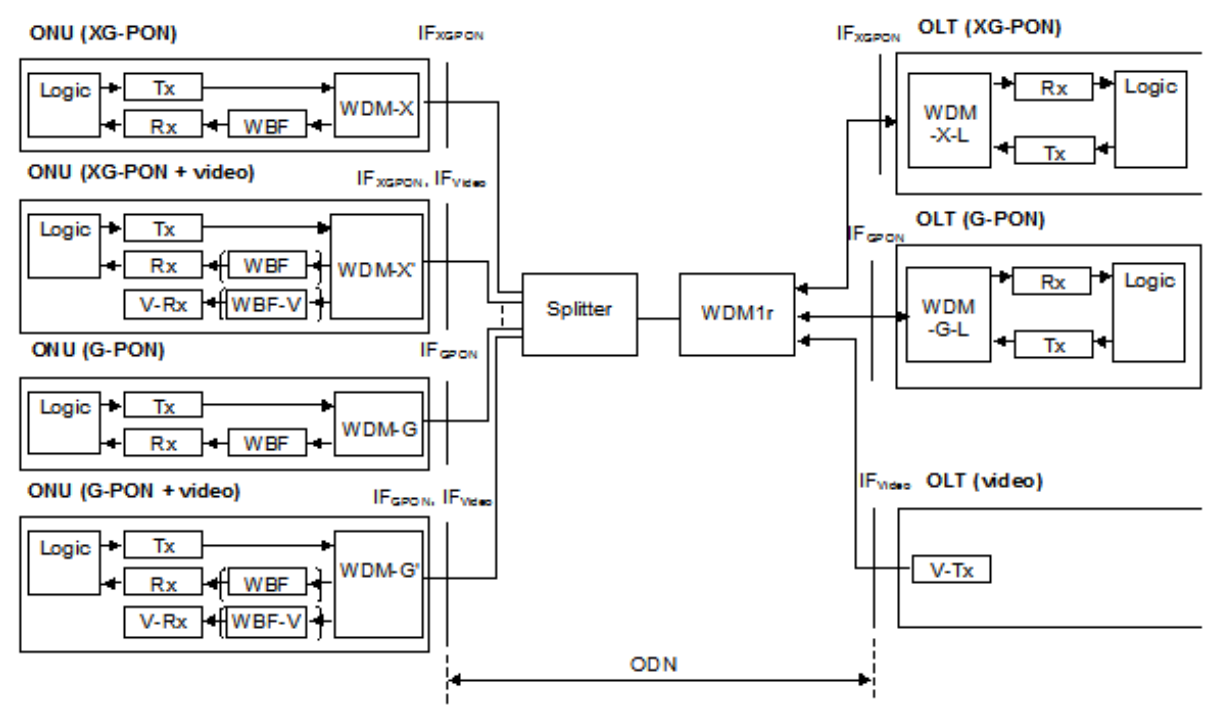

Figure 2 Network Configuration of stack of 10G-PON and G-PON through the WDM1r

\begin{tabular}{|c|c|c|}
\hline Content & GPON & 10G-PON \\
\hline Line rate & $2.5 \mathrm{G} \mathrm{DS} / 1.25 \mathrm{G} \mathrm{US}$ & $10 \mathrm{G} \mathrm{DS} / 2.5 \mathrm{G} \mathrm{US}$ \\
\hline Wavelength plan & $\begin{array}{l}1480-1500 \mathrm{~mm} \text { DS } \\
1290-1330 \mathrm{~nm} \text { US }\end{array}$ & $\begin{array}{l}1575-1580 \mathrm{~nm} \text { DS } \\
1260-1280 \mathrm{~nm} \text { US }\end{array}$ \\
\hline Split ratio & $32 / 64$ & $\geqslant 64$ \\
\hline Max Distance & $\begin{array}{c}20 \mathrm{~km} \\
\text { (Logical: } 60 \mathrm{~km} \text { ) }\end{array}$ & $\begin{array}{c}\geqslant 20 \mathrm{~km} \\
(\text { Logical: } \geqslant 60 \mathrm{~km})\end{array}$ \\
\hline Max Difference Distance & $20 \mathrm{Km}$ & $401 \mathrm{~cm}$ \\
\hline Power budget & $\begin{array}{l}\text { ClassB: } 10-25 \mathrm{~dB} \quad \text { Class B+: } 13-28 \mathrm{~dB} \\
\text { Class } \mathrm{C}: 15-30 \mathrm{~dB} \text { Class C+: } 17-32 \mathrm{~dB}\end{array}$ & $\begin{array}{c}\text { N1 }(14-29 \mathrm{~dB}) \\
\mathrm{N} 2(16-31 \mathrm{~dB}) \\
\text { can be extended to } 33 / 35 \mathrm{~dB}\end{array}$ \\
\hline
\end{tabular}

Figure 3 The physical specifications comparison of $1 \mathrm{G}$ PON and 10G PON 